\title{
A New Technology for Micromachining of Silicon: Dopant Selective HF Anodic Etching for the Realization of Low-Doped Monocrystalline Silicon Structures
}

\author{
C. J. M. EIJKEL, J. BRANEBJERG, M. ELWENSPOEK, AND F. C. M. VAN DE POL
}

\begin{abstract}
In this letter, we report on the use of the sharp selectivity of $\mathrm{HF}$ anodic etching between p-Si and n-Si to realize monocrystalline silicon microstructures, in this case suspended beams, making use of masked implantation of phosphorous for the definition of the geometry. We are convinced that this technology offers new opportunities in the field of micromachining of silicon for micromechanical applications. The technology is complementary to bulk micromachining (anisotropic $\mathrm{KOH}$ or EDP etching, or isotropic $\mathrm{HF} / \mathrm{HNO}_{3}$ etching) and surface micromachining with sacrificial-layer techniques.
\end{abstract}

\section{INTRODUCTION}

$\mathrm{H}$ ANODIC etching of silicon has been used for many years for preparing mirror-like surfaces (polishing), thinning of wafers, and realizing thick porous layers and SOI structures.

Electrochemical and electronic processes near the interface silicon/etchant are involved in the rather complicated reaction mechanism of this etching process. The parameters defining the etch rate are dopant (type and concentration), temperature, applied voltages, HF concentration, and diffusion of reactants and reaction products in the etchant [1].

The etch rate appears to be strongly dependent on dopant concentration (see Fig. 1). Some researchers reported on HF etching for micromechanical applications [2]- [4], all of them making use of $\mathrm{n}$ epilayers on $\mathrm{n}^{+}$substrates and exploiting the selectivity between $n-S i$ and $n^{+}-S i$. Here we report on using the sharp selectivity of HF anodic etching between $\mathrm{p}-\mathrm{Si}$ and $\mathrm{n}$-Si to realize monocrystalline silicon microstructures.

\section{EXPERIMENTS}

Starting with a $(100) \mathrm{p}^{-}$wafer $\left(N_{A}=1.4 \cdot 10^{15} / \mathrm{cm}^{3}\right)$, regions are implanted with phosphorous using positive photoresist as a mask. Fig. 2 shows the doping profile of the phosphorous-implanted regions. After removing the resist and annealing, an aluminum layer is deposited on the reverse side to serve as an ohmic contact to the $\mathrm{p}^{-}$substrate. This

Manuscript received June 19, 1990; revised October 8, 1990.

C. J. M. Eijkel, M. Elwenspoek, and F. C. M. van de Pol are with the University of Twente, 7500 AE Enschede, The Netherlands.

J. Branebjerg is with DANFOSS A/S, DK-6430 Nordborg, Denmark. IEEE Log Number 9041048.

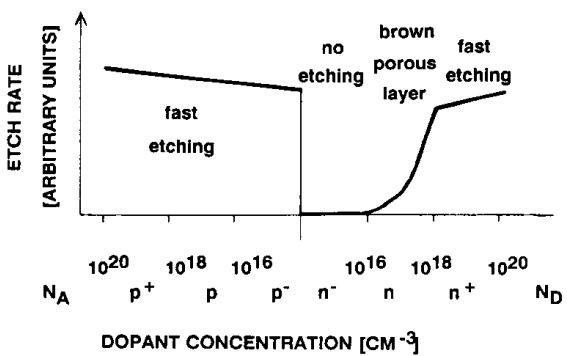

Fig. 1. Etch-rate dependence on dopant concentration for HF anodic etching of silicon (applied voltage in the order of $10 \mathrm{~V}$ ).

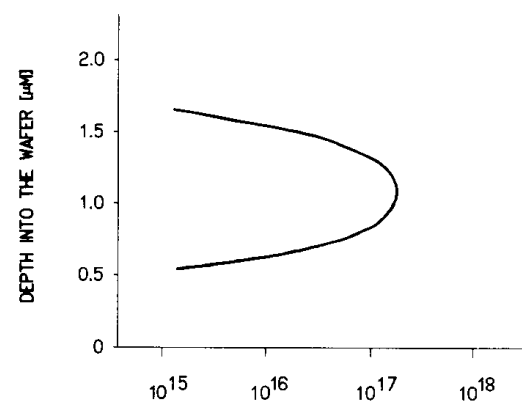

DOPANT (P) CONCENTRATION $\left[\mathrm{CM}^{-3}\right]$

Fig. 2. Doping profile of the phosphorous-implanted regions (after annealing).

aluminum layer is partly covered with a protective resist layer.

The wafer is immersed in a $5 \%$ aqueous HF solution at room temperature (see Fig. 3(a)). A positive voltage of $1.5 \mathrm{~V}$ (with respect to a platinum electrode in contact with the etchant) is applied to the aluminum. The current density at the silicon-solution interface during etching is approximately $0.1 \mathrm{~A} / \mathrm{cm}^{2}$. The surface area being etched is approximately $0.25 \mathrm{~cm}^{2}$, and the size of the platinum electrode is $4 \times 5$ $\mathrm{cm}^{2}$.

Etching is stopped just before the widest beams are completely undercut. The sample structure is depicted in Fig. 3(b). 


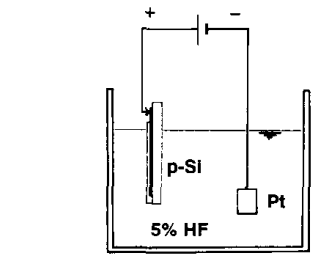

(a)

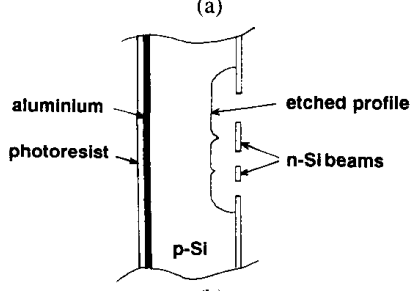

(b)

Fig. 3. (a) Experimental setup for HF anodic etching of silicon. (b) Close-up of the etched wafer; cross-sectional view of the undercut $\mathrm{n}-\mathrm{Si}$ beams.

\section{Results AND Discussion}

Fig. 4(a) shows some etched beams, $1.0 \mu \mathrm{m}$ thick (the thickness of the implanted $\mathrm{n}^{-}$layer as calculated from doping conditions equals approximately $1.1 \mu \mathrm{m}), 2 \mathrm{~mm}$ long, with varying widths $(10,20$, and $30 \mu \mathrm{m})$. The thickness of the beams is very well-defined and uniform (see Fig. 4(b)).

Fig. 1 is valid for applied voltages in the order of $10 \mathrm{~V}$. In our case, the applied voltage is much lower $(1.5 \mathrm{~V})$. Consequently, formation of porous silicon will occur at higher doping levels $\left(N_{D}>10^{18} \mathrm{~cm}^{3}\right)$. The maximum doping level in the implanted layer is approximately $2.2 \cdot 10^{17} / \mathrm{cm}^{2}$. Etching stops as the etch front reaches the edge of the implanted layer where the doping level is low (Fig. 2).

The etch-stop mechanism involved differs from that of the frequently used "p-n stop"' in $\mathrm{KOH}$ etching of silicon. The etch selectivity is due entirely to the doping dependence of etching and not to some effect of the p-n diode; even if the $\mathrm{n}^{-}$layer is contacted, the $\mathrm{n}$-doped silicon is not etched.

The etched surfaces are very smooth (polishing effect). The etching process is isotropic, as can be seen from the curved surfaces at the edges, and the etching rate is approximately $1.5 \mu \mathrm{m} / \mathrm{min}$.

\section{CONCLUSION}

We have shown the feasibility of realizing monocrystalline low-doped silicon microstructures, in this case underetched beams, in an anodic HF etching process by exploiting the dopant selectivity of the etching rate between $\mathrm{p}-\mathrm{Si}$ and $\mathrm{n}-\mathrm{Si}$, using masked implantation of phosphorous in a p-type wafer for the definition of the geometry of the microstructure. The etching process is IC compatible, since no metal ions are present as in alkaline (e.g., $\mathrm{KOH}$ ) solutions. It is a roomtemperature process. Photoresist can be employed as an etching mask since the etchant in this electrochemical process is much milder than in more degrading solutions used for chemical etching of silicon. Unlike electrodeless etching, the etching time can be defined very accurately since the starting and stopping points of time can be controlled by switching the voltage on and off, respectively.

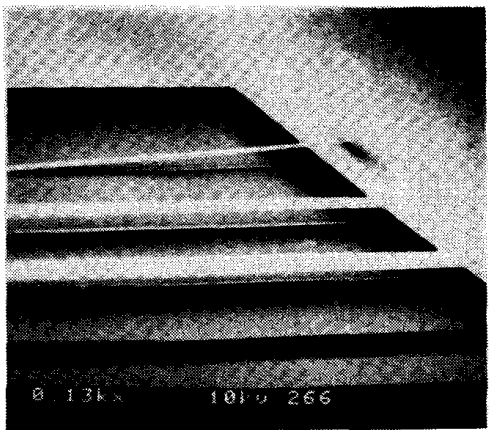

(a)

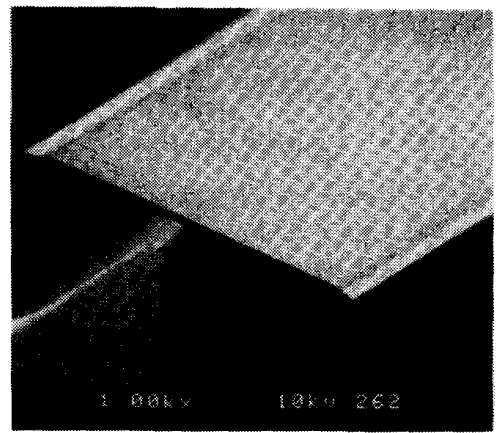

(b)

Fig. 4. SEM micrographs of low-doped n-Si beams realized by HF anodic etching. (a) Underetched beams with varying widths. (b) Close-up of a (broken) almost completely undercut beam, showing the very uniform thickness caused by the strong etching selectivity between $\mathrm{n}-\mathrm{Si}$ and $\mathrm{p}-\mathrm{Si}$.

We are convinced that the technology offers new opportunities in the field of micromachining of silicon for micromechanical applications. It is complementary to the well-known techniques of bulk micromachining (anisotropic $\mathrm{KOH}$ etching or EDP etching, or isotropic $\mathrm{HF} / \mathrm{HNO}_{3}$ etching) and surface micromachining with sacrificial-layer techniques. Its main advantage is the ability to form low-doped monocrystalline structures with well-defined geometries, oriented independent of the crystal orientation, since the etching process is isotropic.

Currently, we are preparing a full paper on this work [5], in which the experiments, results, and electrochemistry of the etching process will be presented and discussed in more detail. A further exploration of the technology is in progress and it is being applied to realize other structures.

\section{REFERENCES}

[1] M. J. J. Theunissen, "Etch channel formation during anodic dissolution of n-type silicon in aqueous hydrofluoric acid," J. Electrochem. Soc., vol. 119, pp. 351-360, 1972.

[2] A. C. M. Gieles and G. H. J. Somers, "Miniature pressure transducers with a silicon diaphragm," Philips Tech. Rev., vol. 33, pp 14-20, 1973.

[3] M. Esashi et al., "Fabrication of catheter-tip and sidewall miniature pressure sensors," IEEE Trans. Electron Devices, vol. ED-29, pp. $57-63,1982$.

[4] B. Hök and K. Gustafsson, "Vibration analysis of micromechanical elements," Sensors and Actuators, vol. 8, pp. 235-243, 1985.

[5] J. Branebjerg, C. J. M. Eijkel, and F. C. M. van de Pol, "Dopant selective $\mathrm{hf}$ anodic etching of silicon-A technology for the realization of single-crystal low-doped micro-mechanical microstructures," to be presented at 4th IEEE Workshop Micro Electro Mechanical Systems, Nara, Japan, Jan. 31-Feb. 2, 1991. 